\title{
INSPIRACIONES BAJO EL ESTAMPIDO DEL CAÑÓN. TENSIONES EN TORNO A LA ESCRITURA DE LA PRENSA EN LOS PERIÓDICOS DE TRINCHERA PARAGUAYOS (1867-69)
}

\author{
Inspirations under the cannon bang. Tensions around the Writing of the Press in the \\ Paraguayan Trench Newspapers (1867-1869)
}

\section{María Lucrecia Johansson}

\section{Resumen}

En este trabajo se estudia cómo, a través de los periódicos de trinchera creados en Paraguay durante el transcurso de la Guerra de la Triple Alianza o Guerra del Paraguay (1864-1870), la lengua guaraní salió del ámbito privado al que había sido confinado para convertirse en un elemento a partir del cual crear una identificación nacional. Durante esa guerra se publicaron en Paraguay periódicos escritos en guaraní con el objetivo principal de captar al nuevo público monolingüe, pero su uso significó además una fuerte revalorización de esta lengua. La edición de periódicos en guaraní significó, por un lado, un intento de trasformación de las relaciones de dominación lingüísticas establecidas en Paraguay antes del estallido del conflicto y, por otro lado, un intento de reivindicación del pasado indígena.

$<$ Prensa $><$ guerra $><$ guaraní $>$

\begin{abstract}
This paper examines how, through the newspapers of trench created in Paraguay during the course of the War of the Triple Alliance or Paraguayan War (1864-1870), the Guarani language went out of the private area in which it had been confined to turn into an element from which creating a national identification. During this war, newspapers written in Guarani were published in Paraguay with the principal aim of catching the new monolingual public, but his use meant in addition a strong revaluation of this language. The edition of newspapers in Guarani meant, on the one hand, an attempt of transformation of the linguistic relations of domination established in Paraguay before the outbreak of the conflict and, on the other hand, an attempt of recovery of the indigenous past.
\end{abstract}

$<$ Press $><$ war $><$ Guarani $>$ 
En la segunda mitad del siglo XIX Paraguay se enfrentó con Argentina, Brasil y Uruguay en una guerra que se conoce como Guerra de la Triple Alianza o Guerra del Paraguay. De acuerdo con Francisco Doratioto ésta guerra, que se extendió entre diciembre de 1864 y marzo de 1870, se convirtió en una verdadera línea divisoria en la historia de las sociedades de los países contendientes; asegura que se trató del conflicto externo de mayor repercusión para los países participantes en cuanto a aspectos políticos y económicos y en lo que respecta a la movilización y pérdida de vidas (Doratioto, 2008). Después de cinco años de guerra Paraguay quedó destruido: no solo perdió el $40 \%$ de su territorio, sino que dos tercios de su población pereció durante el conflicto, de los cuales el $80 \%$ correspondía a la población masculina mayor a los diez años de edad.

Durante ese conflicto el gobierno paraguayo mantuvo un control absoluto sobre la prensa, no solo porque era el dueño de las imprentas y del papel sino que, además, el presidente Francisco Solano López (1862-1870) era quien se encargaba de contratar a los redactores y de señalarles los lineamientos que se debían seguir, proceso que se completaba cuando Solano López aprobaba los artículos propuestos para ser publicados en la prensa (Thompson, 1910).

Los periódicos que se publicaron en Paraguay durante el transcurso de la guerra fueron órganos de propaganda del gobierno. Esto no era un acontecimiento novedoso, por el contrario, el control estatal de la actividad periodística se remonta a la época de la instalación de la imprenta en 1844 y a la aparición de la primera publicación periódica del país, El Paraguayo Independiente, en 1845. Si bien el tradicional control gubernamental de la actividad periodística permaneció inalterable durante la guerra, ésta última generó una situación de crisis de tal magnitud que planteó al gobierno la necesidad de realizar una serie de cambios cuantitativos y cualitativos en la actividad periodística. Fue en este contexto que el gobierno creó nuevos periódicos, a los que calificamos como periódicos de trinchera.

Durante la guerra la necesidad de movilizar moralmente a la población y de garantizar la defensa de la identidad llevaron a que, entre abril de 1867 y febrero de 1869, se publicaran cuatro periódicos: El Centinela (abril 1867 - julio 1868)루, Cabichuí (mayo 1867 - agosto 1868)², Cacique Lambaré (julio 1867 - febrero 1868) ${ }^{3}$ y Estrella

\footnotetext{
1 Se consultó la edición de El Centinela realizada por José Antonio Vásquez arriba citada. Dicha edición no está completa; reúne solo los primeros 36 ejemplares. El Centinela publicó 63 números en total, entre el 25 de abril 1867 y el 9 de julio de 1868. Era publicado los jueves, por la Imprenta Nacional instalada en Asunción.

2 Se consultó la edición facsimilar de Cabichuí compilada por Ticio Escobar y Osvaldo Salerno. Esta colección no está completa, posee 95 números, de los cuales faltan los ejemplares número: 24, 33 y del 49 al 55. Cabichuí se publicó entre el 13 de mayo de 1867 y el 20 de agosto de 1868, en la Imprenta del Cabichuí, instalada en los cuarteles generales de Solano López, primero en Paso Pucú y luego en San Fernando. Apareció con una frecuencia de dos veces por semana.

3 Se consultó la edición facsimilar de Cacique Lambaré, la cual posee 13 números consecutivos. Cacique Lambaré se publicó entre el 24 de julio de 1867 y febrero de 1868, por la Imprenta del Estado establecida primero en Asunción y después en Luque. Se editaba cada 15 o 20 días. En su cuarto número cambió de nombre a Lambaré. La Biblioteca Nacional de Río de Janeiro posee un número 14 del periódico,
} 
(febrero a julio 1869) ${ }^{4}$. Durante el conflicto, en total, llegaron a publicarse cinco periódicos, incluyendo al Semanario de Avisos y Conocimientos Útiles (1853-1869) que venía editándose con anterioridad al comienzo del enfrentamiento.

Además del incremento del número de los periódicos, la actividad periodística se transformó en dos niveles: en la técnica y en el contenido. En el nivel de la técnica, definida ésta como el conjunto de habilidades y aplicaciones (inventos técnicos), se generaron en Paraguay los insumos necesarios para la elaboración de periódicos a partir de materias primas y métodos de fabricación autóctonos. Otra de las innovaciones en el nivel de la técnica fue la utilización del xilograbado, es decir, grabados realizados en madera para ilustrar las páginas de los periódicos. En lo que respecta al contenido, se innovó con la incorporación de textos escritos en lengua guaraní, con tono satírico y acompañado de ilustraciones.

Para el gobierno paraguayo los periódicos de trinchera tuvieron un papel pedagógico, disciplinante, creador de rasgos identitarios. Es por ello que su primer objetivo era llegar al gran público, razón por la cual se revolucionaron las formas y los contenidos de los impresos. Esos cambios fueron introducidos en base a una serie de expectativas atribuidas a ese nuevo público, de allí por ejemplo el uso del guaraní, lengua que hablaba la mayor parte de la población, o el uso de imágenes, que descifraban el mensaje a quienes no sabían leer. Asimismo, una nueva práctica de lectura grupal se impuso con el fin de garantizar la difusión de los periódicos. Esta nueva práctica de lectura se caracterizó por desarrollarse en el ámbito público, sobre todo aunque no exclusivamente en las trincheras, y en voz alta, ya que debía integrar a quienes no sabían leer (Johansson, 2010).

La definición de esas expectativas generó una serie de tensiones que se manifestaron en los periódicos, generando en algunos casos breves debates entre ellos. El presente trabajo se plantea definir cuáles fueron las expectativas que los creadores de los periódicos de trinchera atribuyeron a ese nuevo público al que estaban dirigidos, constituido en su mayoría por soldados que no habían tenido acceso a este tipo de escritos, a partir del análisis de las estrategias utilizadas en la construcción de los escritos periodísticos, centrándonos especialmente en el uso del guaraní en la prensa.

\section{El escritor soldado}

Marcó el inicio de la revolución periodística el periódico El Centinela. Su primer número fue publicado el 25 de abril de 1867 en la Imprenta Nacional, ubicada

con fecha de 16 de marzo de 1868, y se conocen referencias a la existencia de un número 35, con fecha de 15 de septiembre de 1868. Whigham, T. 2012. "Building the Nation While Destroying the Land: Paraguayan Journalism during the Triple Alliance War, 1864-1870", Jahrbuch für Geschichte Lateinamerikas, vol. 49, (en prensa). Se utiliza para este trabajo la traducción del guaraní al español realizada por Wolf Lustig en http://www.romanistik.uni-mainz.de/guarani/cacique/Cacitrad_05.pdf.

${ }^{4}$ Se consultó la colección de 25 números de la Biblioteca Nacional del Paraguay. En total faltan 16 números, específicamente los números: 11, 13, 15, 19 al 21, 23, 24, 27, 29 al 32, 35, 36 y 40. Estrella se publicó entre el miércoles 24 de febrero y el 14 de julio de 1869, por la Imprenta Nacional en las proximidades del cuartel general de Piribebui, con una frecuencia de dos veces por semana. 
en Asunción; a partir de entonces se publicó todos los jueves hasta julio de 1868 . Cada número constaba de cuatro páginas, en las que se insertaban dos grabados; así se convirtió en el primer periódico ilustrado de Paraguay. En su primer número, El Centinela explicó cuáles serían sus metas: informar a la tropa de los episodios de la guerra, defender a la República, celebrar las victorias paraguayas, infiltrarse en las filas del enemigo con el fin de detenerlos y buscar la risa del soldado para alivianar sus fatigas. Otro de los fines explícitos de este periódico fue vigilar a los ciudadanos paraguayos, como lo anuncia en el siguiente fragmento: “Cuando, El Centinela sea relevado se interiorizará en todas partes, observará a los Ciudadanos y no dejará títere con bonete, á quien no toque por pasatiempo, se entiende que elogiando el patriotismo"s.

Ya desde su denominación este periódico aclaraba “que pertenece á las filas del Ejército nacional"6. Incluso el nombre con el que fue bautizado respondió al interés de presentarlo como un soldado más, en guardia, con las funciones de un centinela vigilando tanto a los enemigos como a los ciudadanos desde su mangrullo: "El Centinela" que hoy aparece en el terreno periodístico, es uno de esos soldados jóvenes"7; "El Centinela" pasará á veterano. Hoy es recluta, y despues será soldado viejo"s.

Al mismo tiempo este periódico se presentó como una creación del Mariscal López. El texto que abre el primer ejemplar lleva por título "Dedicatoria al Exmo. Señor Mariscal Presidente"; allí se sostiene que:

"El Centinela", Exmo. Señor, es vuestro soldado. Al nacer os presenta sus armas y os bendice; porque le habeis dado vida, valor, y lo colmais de gloria, sí defiende su puesto con abnegación.

"El Centinela", nacido en medio del estruendo de las armas, y bautizado por el gran Sacerdote de la Patria en la pila del martirio, llevará por emblema el oriflama del republicano, y preconizará las glorias de vuestro génio, y los inmarcesibles laureles, que han conquistado los bravos defensores del Paraguay $^{9}$.

Este "centinela", que presentó sus armas ante el Mariscal López, estuvo subordinado a sus órdenes y le rindió culto de la misma manera que sus compañeros del ejército; así se posicionó, como un compañero en igualdad de condiciones con el resto de la tropa. En estos textos podemos ver como el enunciador indicó su pertenencia a las filas del ejército a la vez que definió a su destinatario privilegiado: el soldado.

\footnotetext{
${ }^{5}$ El Centinela. Año 1, n², 23/04/1867.

${ }^{6}$ El Centinela. Año 1, nº1, 23/04/1867.

${ }^{7}$ El Centinela. Año 1, nº1, 23/04/1867.

${ }^{8}$ El Centinela. Año 1, n²1, 23/04/1867.

${ }^{9}$ El Centinela. Año 1, n¹, 23/04/1867.
} 
El Centinela, que se publicaba simultáneamente con El Semanario, en un primer momento se ubicó como el único órgano producido por el ejército, valiéndose de la identificación con la figura del soldado frente a El Semanario, al que calificaba de "ilustrado":

La felicitación que "El Semanario" ha dirijido al Centinela por su aparicion en el terreno periodistico, es un nuevo estimulo que lo alienta (...) Ojala "El Centinela" no desmienta las nobles y generosas símpatias con que ha sido acogida su aparicion. Y al retribuir la cumplida cortesía de su ilustrado cólega, le hace las protestas del soldado Paraguayo: "de sostener su puesto con honor"10.

Una de las grandes diferencias entre estos periódicos radica en que ambos empleaban en sus artículos diferentes "tonos", como bien lo hace notar José Antonio Vázquez. Mientras que el Semanario fue el "tradicional y mensurado periódico (que) no podía descender de tono ni desprenderse de su carácter oficial", El Centinela fue "una hoja de tono menor, de nivel popular y satírico", que vino a ocupar un lugar vacante por medio del empleo de un "vocabulario general a la par que el oficial" (Vázquez, 1964).

Otra de las estrategias de El Centinela tendientes a la construcción de su perfil como "un soldado más" se manifestó cuando destacó su dominio de la "táctica militar", a la vez que se definía ajeno al "dominio de perfeccionadas habilidades técnicas para el manejo de la escritura":

El motivo, caros lectores, que me mueve á bajar (...) á la arena periodística ó literaria, es el contaros varias cositas (...) y formar sobre ellas mi humilde juicio; en fin como yo no he aprendido otra cosa (aparte de la táctica militar y del arte de lanzar cortes y esquivar quites, en el cual nadie me saca la punta, ni me echa el pie adelante): hago letras (...) dispongo estos garabatos en formación de batalla por columnas cerradas; póngole puntos y comas, según mis conocimientos en la materia, pues cada uno estornuda como Dios lo ayuda (...) me cabe la dicha de agradar (según creo) á mis valientes compatriotas y compinches ${ }^{11}$.

En esta cita se desnudan las relaciones de dominación lingüística que regulaban no solo a la prensa paraguaya sino la sociedad en su conjunto. Por un lado, tenemos un periódico orgulloso de su lenguaje elevado, variedad legítima dentro del ámbito intelectual. Por el otro, tenemos una nueva clase de periódico que al estar dirigido a otro público, en particular a los soldados, utilizó un lenguaje más adecuado a sus destinatarios pero que no correspondía al nivel de formalidad esperable en una publicación periodística, sino que disponía "garabatos en formación de batalla".

\footnotetext{
${ }^{10}$ El Centinela. Año 1, n², 2/05/1867.

${ }_{11}$ El Centinela. Año 1, n5, 23/05/1867.
} 
Sin embargo, ambos periódicos tuvieron como redactores a personas de instrucción superior, familiarizadas con el manejo de lenguas extranjeras y con los repertorios clásicos de la cultura erudita, formados en las instituciones educativas creadas durante el gobierno de Carlos Antonio López. Durante su gobierno, creció el número de individuos que tuvieron acceso a ciclos cada vez más prolongados y exigentes de educación formal. A través de la creación de instituciones educativas de diferentes niveles y del envío de jóvenes paraguayos para perfeccionarse en Europa, se formó un conjunto de individuos que adquirieron capital escolar, que constituye la forma más palpable e institucionalizada de capital cultural (Altamirano, 2002). Los individuos formados en estas instituciones fueron reclutados como redactores de los periódicos de trinchera, llegando a trabajar simultáneamente para más de un periódico.

Los editores y redactores de los periódicos de trinchera fueron conscientes de su deber de crear un nuevo tipo de órgano periodístico, y así buscaron innovar, entre otras cosas, el vehículo de expresión que utilizaban, tratando de adecuar su lenguaje a la variedad que consideraban propia del nuevo público al que se dirigían. En ocasión de la celebración de un año de publicaciones, Cabichuí sostuvo haberse: “(...) dedicado á la noble tarea de recoger las hazañas de las armas nacionales para trasmitirlas á la prosperidad con los vivos colores que solamente puede empastar el escritor soldado, que recibe las inspiraciones bajo el estampido del cañon"12.

Durante la guerra lo que importó a la práctica periodística paraguaya no fue la pertenencia de sus redactores a un círculo letrado sino su proximidad con los campos de batalla. Este nuevo actor, el "escritor soldado", consideraba que cuanto más cerca se encontraba del escenario del enfrentamiento, mejor era la información que podía brindar.

Cabe destacar que los artículos publicados en El Centinela, en Cabichuí y en el Cacique Lambaré, carecían de la firma del redactor, situación que cambió recién con la aparición de Estrella, donde encontramos letras mayúsculas como: B. T. S. T. o Z., a manera de firma de cada artículo ${ }^{13}$. En Cabichuí, (voz guaraní que significa avispa) que tuvo como principal colaborador al Generalísimo Cabichuí, los nombres de los "corresponsales" eran también nombres de otras especies de avispas: cabytá, cahú, mamangá, cabáguará. En El Centinela encontramos cartas que llevan la firma de los personajes-símbolos construidos por el periódico, como por ejemplo El Centinela Mateo Matamoros, El inválido, El Cristiano Viejo, El Corresponsal.

De manera consecuente con la estrategia utilizada por El Centinela de definirse como un soldado que hacía la guerra a través de las palabras, el redactor o redactores de sus artículos eran presentados también como soldados o familiares de soldados desprovistos de capital cultural, en cuanto que no pertenecían a la categoría de letrados. $\mathrm{Al}$ manifestar la diferencia existente entre el tipo de lenguaje que se emplea en este

12 Cabichuí. Año 2, n85, 13/05/1868.

13 "Los redactores señalarán cada uno de sus artículos con una letra alfabética, para que tengan el gusto de reconocer y recorrer mas fácilmente sus escritos”. Estrella, Año 1 n¹, 24/02/1869. 
periódico con el que es el "propio" de la prensa, el redactor del artículo arriba citado manifiesta una actitud condescendiente con respecto a las relaciones de dominación lingüística. Para Pierre Bourdieu, la condescendencia es la utilización demagógica de una relación de fuerza objetiva, ya que el que condesciende utiliza la jerarquía para negarla, y en el momento mismo en que la niega la está explotando(Bourdieu, 1990).

Volvemos a encontrar estas tensiones entre lenguaje culto y lenguaje popular en el segundo periódico editado en el marco de esta revolución periodística: Cabichuí, el que apareció apenas transcurrido un mes de la publicación del primer número de $E l$ Centinela. Este nuevo periódico fue presentado también como un soldado, que al igual que El Centinela, carecía de un lenguaje culto:

"El "Cabichui" es, pues, un soldado, y al presentarse en el palenque del periodismo (...) humilde en sus pretensiones literarias, solo viene empujado por su amor de Patria á tomar una plaza para combatir a favor de la idea que ha levantado á toda la República, y á correr tras los laureles que alcanza la decision en la guerra de los libres contra los esclavos" ${ }^{\prime 14}$.

Así vemos que el capital cultural necesario para encarar la actividad periodística es resignado en favor de la voluntad de luchar por la patria. Esta fue una de las estrategias a través de las cuales los periódicos convirtieron la profesión del soldado en la encarnación de todo lo positivo, resolviendo con claridad su postura sobre el tópico clásico de las armas y las letras: "El hombre consagrado al saber, es útil, pero no arrostra los sacrificios del soldado. Y sin embargo este se contenta con una hoja de laurel y lleva el galardon de sus fatigas en una medalla pendiente al cuello"15.

El periódico Cabichuí, elaborado primero en el campamento de Paso Pucú y luego en el de San Fernando, puso en evidencia que su particularidad era ser publicado en el campamento militar, de allí que aclare: "Su vida será la del verdadero soldado en campaña y al frente del enemigo"16.

Al salir Cabichuí se presentó primero ante Solano López, saludándolo con "ardoroso entusiasmo". Saludó además "al veterano "Semanario" y al recluta Centinela"17. Si bien, Cabichuí se definió en un principio como un periódico "humilde", de "tono chistoso y alegre", aclaró luego "no ser tan humilde que no conozca sus meritos, ni tan soberbio que desconozca sus fallas"18, por lo que no perdió oportunidad de criticar al "ilustrado Semanario" debido a la aparición de términos inexistentes en sus artículos ${ }^{19}$.

\footnotetext{
${ }^{14}$ Cabichuí. Año 1, nº1, 13/05/1867.

${ }^{15}$ El Centinela. Año 1, n5, 23/05/1867.

${ }^{16}$ Cabichuí. Año 1, n²1, 13/05/1867.

${ }^{17}$ Cabichuí. Año 1, n²1, 13/05/1867.

${ }^{18}$ Cabichuí. Año 1, n², 16/05/1867.

19 "Comotora- ¡Qué contento! Se decia el "Cabichuí" viendo a un camarada que estaba fojeando un reverendo volúmen de á folio mayor: este era el Diccionario de la lengua castellana por la Academia
} 


\section{Lenguas en conflicto}

El Centinela había incluido por primera vez en la historia del periodismo paraguayo un texto en guaraní, el cual llevaba por título "Carta del Centinela á su esposa”. Si bien en El Centinela no fue frecuente la publicación de textos íntegramente escritos en guaraní, sí es común encontrar palabras sueltas para referirse a toponimias, vegetales, armas y nombres propios de persona. De los treinta y seis números analizados, solo en diez de ellos se encuentran textos escritos en guaraní, tratándose de poemas o cartas. Los poemas, mayormente satíricos, conforman la mayor parte de los textos en guaraní. En total se publicaron cuatro cartas en guaraní, todas ellas firmadas por El Centinela Mateo Matamoros, un soldado que se comunica con su familia y amigos en su propia lengua para referirles aspectos de la vida cotidiana en un campamento militar. Dos de estas cartas están dirigidas a Miguela, su esposa; otra a Matías, su hermano y la restante a Rosa, una compañera de la infancia. El hecho de que El Centinela Mateo Matamoros escriba en guaraní resulta especialmente significativo ya que este es el personaje-símbolo que da nombre al periódico y que aparece como responsable ficticio de la mayor parte de los artículos publicados.

Desde sus páginas El Centinela sostuvo que el guaraní era la lengua nacional, por lo que debía ascender al rango de las lenguas de las civilizaciones modernas:

“Todos los pueblos de la tierra tienen su idioma peculiar. -La palabra es uno de los distintivos del ser racional (...) Hablando el idioma nativo nos parece estar bajo el techo de nuestros Padres, recibiendo sus primeros cariños. Por eso "El Centinela" de vez en cuando hablará en su querido guaraní; por que asi se espresará con mas gusto en su propia lengua"20.

También en Cabichuí encontramos coplas, poemas y diálogos escritos en guaraní, dedicados a denostar y ridiculizar al enemigo. Los diálogos en guaraní aparecieron cuando los habitantes del Paraguay eran los que tomaban la palabra. Cabichuí trascribió los comentarios que los soldados paraguayos hacían entre sí al momento de leer el periódico. Podemos considerar que esta fue una de las estrategias a partir de las que Cabichuí procuraba adquirir verosimilitud frente a su público.

A través de la publicación de estos diálogos en guaraní encontraron también sitio en Cabichuí escenas de la vida cotidiana más allá de los campos de batalla. Por ejemplo, encontramos un diálogo entre dos ancianas comadres Ñ Sabeli y Tia Condé, que conversan de mañana mientras toman "un gordo mate". Cabichuí, que las "había

Española. Había, pues, el camarada leído el "Semanario" y tópase con el término comotora, cuyo significado no pude siquiera adivinar, y es con este motivo que se desgañitaba, buscándolo en su Diccionario. Entonces el "Cabichuí" se le acercó y dijo: semejante término acaso pueda existir en el Diccionario de Martinez López, en el catálogo que trae de las erratas en Valbuena y desatios en Salvá, que parece ser por ahora el manual favorito de los cajistas de la Imprenta del "Semanario". Cabichuí. Año 2, n87, 25/05/1868.

${ }^{20}$ El Centinela. Año 1, n¹, 25/04/1867. 
estado escuchando", transcribe en guaraní el diálogo entre ambas para sus lectores, "sin comentarios ni garantías". Esta escena es acompañada en el periódico con un grabado, en el que tanto las vestimentas como la arquitectura de las edificaciones evidencian la voluntad de los grabadores de ilustrar actores, costumbres y escenarios típicos del Paraguay (Figura 1).

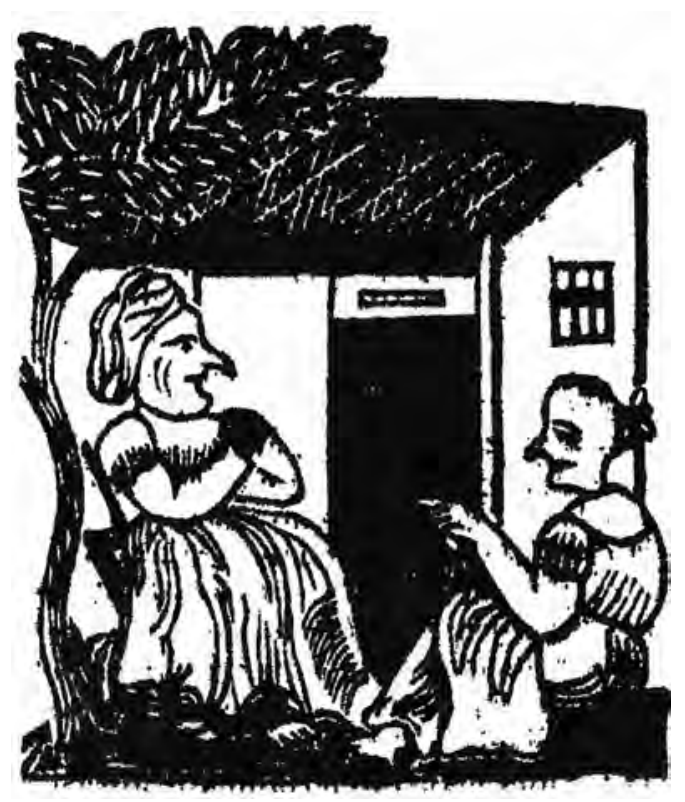

Figura 1. Fuente: Cabichuí, Año 1, № 16, 04/07/1867.

A diferencia de El Centinela y Cabichuí, en las páginas de Cacique Lambaré predominó el guaraní y solo ocasionalmente aparecieron palabras en español. Según José Antonio Vázquez, la aparición de este último periódico fue una confirmación del éxito de las cartas y versos en guaraní que se intercalaban en las columnas de los dos periódicos predecesores (Vázquez, 1964).

Cabría preguntarse si con la aparición de Cacique Lambaré, periódico escrito íntegramente en guaraní, hubo un intento de transformación de las relaciones de dominación lingüística propias de la sociedad paraguaya. Si el español fue la lengua legítima en las prácticas sociales letradas, vinculadas sobre todo a la burocracia y a la escuela desde la colonia y durante toda la historia de Paraguay como país independiente, con la guerra el guaraní comenzó a difundirse a través de estos periódicos. Es en la prensa de trinchera donde se reflejó el cambio de actitud con respecto al guaraní, ya que estos impresos comenzaron a considerarlo como la lengua nacional. Debemos considerar en este punto a quién le interesaba revertir las relaciones de dominación lingüística y cuáles fueron las intenciones que guiaron este accionar. 
En su edición número uno Cabichuí se definió como un "guaraní neto", motivo por el cual no podía "abandonar sin mortificarse mucho el delicioso idioma de sus padres" citadas y afirmó que este nuevo periódico al lanzarse al palenque de la lucha "con su propio lenguaje": "tiende a hacer revivir, y abre un camino para esplorar la literatura guaranî"22.

Antes del estallido de la guerra, en Paraguay se había adoptado el castellano como lengua de la burocracia y del sistema educativo, desplazando al guaraní al ámbito doméstico, atribuyéndole un papel subordinado en el mundo de la cultura paraguaya ${ }^{23}$. Mientras el guaraní era la lengua que se hablaba tanto en la ciudad como en el campo, el español era aprendido en las instituciones educativas, por lo que su conocimiento quedó limitado a una minoría caracterizada por su pertenencia al ámbito urbano, por su sexo masculino y por su posición social elevada ${ }^{24}$. El español trató de imponerse como lengua portadora de prestigio social a través de la negación del guaraní. Juan Crisóstomo Centurión relata en sus memorias los días en la escuela del maestro Quintana, donde:

\begin{abstract}
"Se prohibía hablar en ella, en las horas de clase, el guaraní, y al fin de hacer efectiva dicha prohibición, se había distribuido a los cuidadores o fiscales unos cuantos anillos de bronces que entregaba al primero que pillaba conversando en guaraní. Este lo traspasaba a otro que hubiera incurrido en la misma falta y así sucesivamente durante toda la semana hasta el sábado, en que se pedía la presentación de dichos anillos, y cada uno de sus poseedores como incurso en el delito, llevaba el castigo de cuatro o cinco azotes, alzado al hombro de alguno de sus compañeros" 25 .
\end{abstract}

Durante la guerra de la Triple Alianza la prensa realizó el traslado del guaraní desde la esfera privada a la esfera de lo público, transformándolo en el "lenguaje del héroe”. Así, estos periódicos de trinchera se propusieron invertir la relación existente entre el español y el guaraní, lo que fue claramente expresado en Cacique Lambaré:

"Dicen que hay todavía escueleros de antaño que no quieren saber nada de lo que se escribe en nuestro idioma. Que sepan

\footnotetext{
${ }^{21}$ Cabichuí. Año $1, n^{\circ} 1,13 / 05 / 1867$.

${ }^{22}$ Cabichuí. Año 1, n²27, 08/08/1867.

${ }^{23}$ En 1848 Carlos Antonio López declaró extinto el régimen de comunidades indígenas y desterró también el uso de los apellidos en guaraní. "Ahora traían un nombre español, habían dejado de ser indios, pero hablaban en guaraní”. Meliá, Bartomeu. 1992. La lengua guaraní del Paraguay. Historia, sociedad y literatura. Madrid, Mapfre, p. 167.

${ }^{24}$ En 1812 la Junta Gubernativa elevó un documento titulado "Instrucciones para Maestros de Escuela", en donde se establecía que el guaraní debía ser desterrado de las aulas. Años más tarde, el español Ildefonso Bermejo consideraba que unas de las fallas del sistema educativo de Carlos Antonio López se encontraba en los maestros que no dominaban el castellano con fluidez y corrección.

${ }^{25}$ Centurión, Juan Crisóstomo (sin fecha de ed.) Memorias o reminiscencias históricas sobre la Guerra del Paraguay, Asunción, Ed. Guarania, Tomo I, pp. 61-62.
} 
ellos que en la escuela de hoy ya no hay látigo para los que hablan en guaraní. Ya no hay "lista de los que han hablado en guaraní” - Eso se acabó, ya no hay ninguna razón para despreciar nuestro idioma, sin menoscabo del castellano"26.

El primer número de Cacique Lambaré sostuvo que saldría escrito íntegramente en guaraní: "nuestro dulce idioma, esa lengua que queremos tanto y que hemos mamado

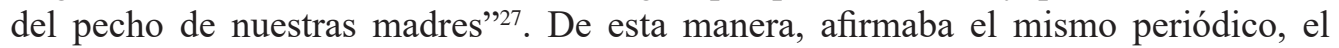
idioma guaraní "haría su entrada entre las lenguas de los países más importantes².

Bartomeu Meliá sostiene que fue la guerra la que obligó a Solano López a cambiar la política lingüística que habían mantenido sus antecesores (Meliá, 1992). El pueblo paraguayo se volcó a su lengua vernácula en un momento en el cual se necesitaba alcanzar una unidad fuerte contra un enemigo en común. Una opinión similar expresa en sus memorias Juan Crisóstomo Centurión:

"la guerra de 1864 a 1870 se nutrió con la sonora armonía del idioma autóctono (...) El drama hondo y terrible, la tragedia singular de aquella época los sufrió, así, el pueblo paraguayo, en guaraní. Era la lengua en la que lloraban las mujeres de la residenta y en la que odiaba y peleaban los varones de nuestra tierra" 29 .

Algunos autores han atribuido a factores emocionales el uso del guaraní en los periódicos de trinchera. Consideran que esta lengua actuó como un factor aglutinante que sirvió para mantener encendido cierto ardor patriótico frente a la superioridad numérica y armamentística de las tropas aliadas, fortaleciendo la moral de la tropa y cohesionando al ejército paraguayo. Caballero Campos y Ferreira Segovia sostienen que la razón por la cual el guaraní salió del olvido y de la postergación de su uso escrito fue el deseo de afianzar la identidad y robustecer el sentimiento nacionalista, frente a la disyuntiva histórica de sobrevivir como país independiente (Caballero Campos y Ferreira Segovia, 2007). Así, el guaraní sirvió a la afirmación de rasgos identitarios, convirtiéndose en un signo distintivo de cohesión y fortaleza ante lo foráneo, sospechoso y desconocido.

Delicia Villagra-Batoux afirma que López "tuvo la cordura de saber reconocer el peso del guaraní en la conciencia y en los sentimientos de sus compatriotas. Lo elevó al rango de símbolo de identidad paraguaya y tomó las medidas para que la lengua sea sentida a la vez como un elemento unificador del patriotismo y como un patrimonio a defender" (Villagra-Batoux, 2002). Asimismo, señala que el uso del guaraní se vinculó con una estrategia militar: al ser el guaraní un código lingüístico de dominio casi

\footnotetext{
${ }^{26}$ Cacique Lambaré, Año 1, n³, 22/08/1867.

${ }^{27}$ Cacique Lambaré, Año 1, n¹, 24/07/1867.

${ }^{28}$ Cacique Lambaré, Año $1, n^{\circ} 1,24 / 07 / 1867$.

${ }^{29}$ Centurión, J.C. Op. cit., Tomo III, p. 143.
} 
exclusivo de las tropas paraguayas brindó al ejército paraguayo la seguridad de que sus mensajes quedaban celosamente resguardados.

Por otra parte, José Antonio Vázquez relaciona el uso del guaraní con una etapa particular de la guerra: “cuando las familias pudientes del país, sin excluir los altos miembros de la Administración Pública y los propios parientes del Mariscal López, en el intento de salvar sus intereses personales de las fauces insaciables de una guerra que consideraban perdida de antemano (...) comenzaban a insinuarse en la intimidad como partidarios de la paz, y por ende, en su condición de derrotistas latentes". De esta manera el uso del guaraní "traducía la perentoriedad de dirigirse a las clases más profundas y populares de la República, que eran los nervios y el sudor de la resistencia nacional" (Vázquez, 1964).

Para Josefina Plá, en cambio, la utilización del guaraní encuentra su causa en la necesidad de comunicarse con toda la población (Plá, 1984). Es decir, que el uso del guaraní como vehículo de expresión buscó subsanar el desconocimiento que tenían los soldados del idioma castellano ${ }^{30}$. Solano López vio al idioma guaraní como un instrumento de comunicación amplio e integrador ${ }^{31}$. Por lo tanto, el uso del guaraní no era una conveniencia sino una necesidad.

Bartomeu Meliá afirma que en el interior de Paraguay la gran masa de la población ignoraba el español; incluso en Asunción había quienes no lo conocían en absoluto, y quienes sí lo dominaban se limitaban a utilizarlo solo con extranjeros. Meliá sostiene entonces, que "hasta la guerra del '70 el Paraguay era un país donde el guaraní era la única lengua, como hecho social nacional” (Meliá, 1992).

Cuando los periódicos de trinchera comenzaron a hacer un uso escrito del guaraní se enfrentaron con el problema de la falta de estandarización de esta lengua. Por este motivo, Solano López llamó a una convención en Paso Pucú el 18 de mayo de 1867. Allí se encargó a una comisión ${ }^{32}$ la tarea de establecer una ortografía para la escritura del guaraní y resolver las irregularidades y defectos que se presentaban en los periódicos con respecto a la redacción de vocablos en guaraní33.

Dionisio González Torres realizó un análisis de la grafía del guaraní implementada en los periódicos de trinchera que lo llevó a concluir que, a pesar de los

\footnotetext{
${ }^{30}$ Cabe recordar que Manuel Belgrano, cuando entró en Paraguay en 1810, dirigió proclamas en guaraní, a sabiendas de que esta era la lengua que usaba la mayoría de la población.

31 "Indudablemente, el impulso otorgado por el presidente Francisco Solano López para la utilización del idioma Guaraní en las comunicaciones escritas de las trincheras estuvo muy vinculado a su propia afección y formación académica políglota absorbidas desde muy joven para con el aprendizaje de idiomas. Aparte de hablar el francés, el inglés y el portugués, dominaba al grado de fluidez tanto el español como el guaraní". Caballero Campos, Hérib y Ferreira Segovia, Cayetano. 2007. "El Periodismo de Guerra en el Paraguay (1864-1870)". En: Richard, Nicolas, Capdevila, Luc y Boidin, Capucine (dir.). Les guerres du Paraguay aux XIXe et XXe siècles. París, CoLibris.

${ }^{32}$ Integrada por Luis Caminos, Carlos Riveros, Andrés Maciel y Juan Crisóstomo Centurión. González Torres, Dionisio. 1989. Sobre la grafia del Guarani-Revisión bibliográfica desde el siglo XVI. Asunción, S.P.I., p. 6.

${ }^{33}$ Dionisio González Torres menciona que los resultados de dicha ortografía se perdieron con el paso del tiempo. González Torres, D. Op. cit., p. 7.
} 
intentos de estandarización, hubo muy pocos cambios con respecto a la grafía anterior a ese congreso ${ }^{34}$. En realidad, la normatización de la ortografía guaraní se logró recién en la segunda mitad del siglo XX, tras los congresos científicos de la década de $1950^{35}$.

El problema que originó la falta de una norma fijada para la escritura del guaraní llevó a que en varios artículos el Cacique Lambaré tuviera que explicar la ortografía que empleaba, e incluso apelar a los otros periódicos que usaban el guaraní en sus páginas con el fin de resolver grafías dudosas ${ }^{36}$. No obstante, esta preocupación por el establecimiento de una norma ortográfica ocupaba un lugar de menor importancia debido al contexto de guerra:

"Y ahora en su segunda edición les explica lo siguiente a Cabichui y Centinela, y espera que ellos le aclaren el mejor camino. Uno dice iiyba, iaieby; otro dice ijyba, jajeby. El Cacique les quiere pedir, siempre que sea posible, que haya un avance en estas cosas. Quiere saber si en tales palabras tiene que usar $i$ o $j(. .$.$) Al final lo deja todo al criterio de$ Cabichui y Centinela, y mientras se pongan de acuerdo seguirá con la $j$ - latina como al principio (...) Lambaré dice: estas cosas no son para ahora, la tarea que nos toca ahora es de día y de noche azotar a los negros. Que quede, pues, para otro día"37.

Este periódico especificó que no insertaría palabras en otras lenguas a menos que éstas no tuvieran traducción al guaraní. A tono con este propósito purista expuso que:

${ }^{34}$ González Torres señala que en El Centinela, Cabichuí, Cacique Lambaré y Estrella siguió la confusión sobre el uso de la "y", para representar el sonido gutural; "h", para la aspiración; "j”", para la ye; "k", para la c dura y los acentos para la nasalización.

${ }^{35}$ El guaraní paraguayo adoptó un alfabeto fonológico unificado recién en 1950, en conjunto con los demás países de la región guaraní, en un congreso de especialistas realizado en la ciudad de Montevideo. Este alfabeto, que generó una polémica de medio siglo, fue adoptado ante la ausencia de un alfabeto tradicional y sobre la base de los alfabetos populares que representaban demasiadas dificultades, por ser todos ellos adaptaciones improvisadas del abecedario castellano. Zarratea, T. 2002. Gramática elemental de la Lengua Guaraní. Asunción, ed. Marben, p.30.

36 "Notificación. Para que se pueda leer con mayor facilidad y corrección esta revista y si todavía no hay manera para cambiarlo, vamos a usar a partir de ahora los siguientes "signos": $1^{\circ}$. Si una palabra termina en vocal, pronunciaremos fuerte esta última letra normalmente sin acento: así tatá (fuego), tobé, carumbè. $2^{\circ}$. Una letra que lleva encima esto / la pronunciaremos fuerte, así: ndipóri (no hay), heí, ahyó. $3^{\circ}$. Las que llevan encima esto \, las pronunciaremos por la nariz: Tùpà (Dios), pèteì, pòrà. $4^{\circ}$. En cuanto no dispongamos de $\mathbf{y}$ con acento, usaremos esta $\boldsymbol{y}$ [cursiva] en las palabras semejantes a éstas: yma (antes), kyyì (agí), hey (huso). $5^{\circ}$. Este diacrítico $\wedge$ se usará en letras al interior de palabras nasales, para acentuarlas de la siguiente forma âgà (alma), ñèê, kàê. $6^{\circ}$. Esta y la pronunciaremos por la boca, y se usará para decir: yby (tierra), teyi (descendiente), ybate, kyryryo. $7^{\circ}$. Esta letra i servirá como consonante y no como vocal, según lo exija la palabra; así leeremos las siguientes: iepeá (leña), iai (matorral). Lambaré, Año 1, n5, 16/09/1867.

${ }^{37}$ Cacique Lambaré, Año 1, n², 08/08/1867. 


\begin{abstract}
“es necesario que usemos siempre nuestro idioma hasta donde sea posible. Haremos como los españoles: antiguamente su lengua se fundió con el latín, y desde entonces, poco a poco, fue evolucionando hasta quedar bien, aunque tomando palabras de otras lenguas, como por ejemplo polisílabo; esta es una palabra griega, pero el español la prestó, siendo imposible decir la mismo en su propia lengua (...) Así lo haremos nosotros también, pero no está bien que se usen sin necesidad palabras latinas, castellanas o de otras lenguas con la nuestra, para que ésta conserve su máxima pureza posible"38.
\end{abstract}

Asimismo, Cabichuí sostuvo que el Cacique Lambaré debía uniformar: "el uso de las letras en guaraní (...) rectificando la ortografía antigua que, á mas de ser insuficiente, presenta muchas dificultades"39. Si bien, el Cacique Lambaré no logró el cometido que tanto Cabichuí como El Centinela sostuvieron que debía tener de "regularizar el idioma (guaraní), haciendolo mas general en sentido ortográfico" "40, sí logró una exaltación de las raíces indígenas del Paraguay.

\title{
El bravo cacique ha despertado
}

Junto a esta reivindicación de la lengua ancestral, asistimos a una exaltación de costumbres tradicionales y personajes históricos indígenas por parte de la prensa. Un ejemplo lo constituye el Cacique Lambaré, un indígena guaraní que pasó a la historia como símbolo de la resistencia en su lucha contra la entrada y el establecimiento de los españoles.

De acuerdo con Wolf Lustig, la lengua fue el nexo que permitió establecer una conexión entre las hazañas guerreras de antaño y el contexto de guerra ${ }^{41}$, construyendo una filiación genealógica con "la raza guaraní, esa raza de primitivos guerreros" " Lo guaraní se construyó en la intersección de una lengua y la etnia que la hablaba, de tal manera que la reivindicación de una acarreaba la revalorización de la otra, y este proceso llevó a entroncar la identidad nacional paraguaya con sus raíces indígenas, poniendo de relieve el rasgo constitutivo de nación guerrera (Lustig, 2007). Esto aparece en la siguiente afirmación de El Centinela:

“ ¡Si! Hablaremos nuestro idioma, no nos correremos, como

el grajo, de nuestra propia lengua ni tomaremos las plumas

de otras aves para adornarnos, desdeñando las nuestras.

\footnotetext{
${ }^{38}$ Lambaré, Año 1, n4, 05/09/1867.

${ }^{39}$ Cabichuí. Año $1, n^{\circ} 31,22 / 08 / 1867$.

${ }^{40}$ El Centinela. Año 1, nº15, 01/08/1867.

${ }^{41}$ Lustig, Wolf. 2007. “¿El guaraní lengua de guerreros? La raza guaraní y el avañe’e en el discurso béliconacionalista del Paraguay”. En: Richard, Nicolas, Capdevila, Luc y Boidin, Capucine (dir.). Les guerres du Paraguay aux XIXe et XXe siècles. París, CoLibris.

${ }^{42}$ El Centinela. Año 1, nº4, 16/05/1867.
} 
Cantaremos en guaraní nuestros triunfos y nuestras glorias, como cantaron en otro tiempo su indómita bravura, los descendientes de Lambaré y Yanduazubí Rubichá" ${ }^{43}$.

Si El Centinela y Cabichuí se presentaron como simples soldados paraguayos que tomaban la pluma para luchar también por medio de las palabras contra sus enemigos, Cacique Lambaré, en cambio, se presentó como la resurrección del Cacique guaraní:

Sí, yo soy Lambaré, vuestro antepasado, el tan famoso entre los caciques de antaño (...) Cuando vinieron los señores desde España, yo peleé junto con ellos como pude, defendiendo nuestra Patria ${ }^{44}$.

Hace tres siglos Lambaré, junto con su gente, defendió su tierra: ahora tiene por qué salir de su sepultura para pelear también entre nosotros ${ }^{45}$.

Por ello la figura de este antiguo Cacique fue utilizada para dar nombre y encarnar al editor ficticio del periódico homónimo. En El Centinela se menciona que:

El título del nuevo cólega es el Cacique Lambaré, y nos recuerda el valiente guerrero de ese nombre que combatió á Ayolas á su arribo á estas comarcas, y que despues hizo las paces aliándose con los Españoles. El bravo cacique ha despertado, despues de un sueño secular, y se nos presenta su efigie, en trage indigena, con el arco y las flechas del estado primitivo, parado al pie del cerro que lleva su nombre (...) y nos prodiga sabios consejos tan propios de un antiguo guerrero ${ }^{46}$.

En sus tres primeros números Cacique Lambaré llevó el siguiente dibujo en su primera página (Figura 2).

En este grabado vemos al Cacique Lambaré señalando el pozo vacío que antiguamente fuera su tumba; en el costado derecho vemos a "su cerro", desde el cual mira "con mucha atención a todos los lados, porque en estos momentos no debemos dormir" $"$.

La vinculación entre la lucha con los españoles y la guerra contra la Triple Alianza realizada por Cacique Lambaré fue criticada por Cabichuí:

\footnotetext{
${ }^{43}$ El Centinela. Año 1, nº4, 16/05/1867.

${ }^{44}$ Cacique Lambaré, Año 1, n¹, 24/07/1867.

${ }^{45}$ Cacique Lambaré, Año 1, n ${ }^{\circ}$, 24/07/1867.

${ }^{46}$ El Centinela. Año 1, n¹5, 01/08/1867.

${ }^{47}$ Cacique Lambaré, Año 1, n¹, 24/07/1867.
} 


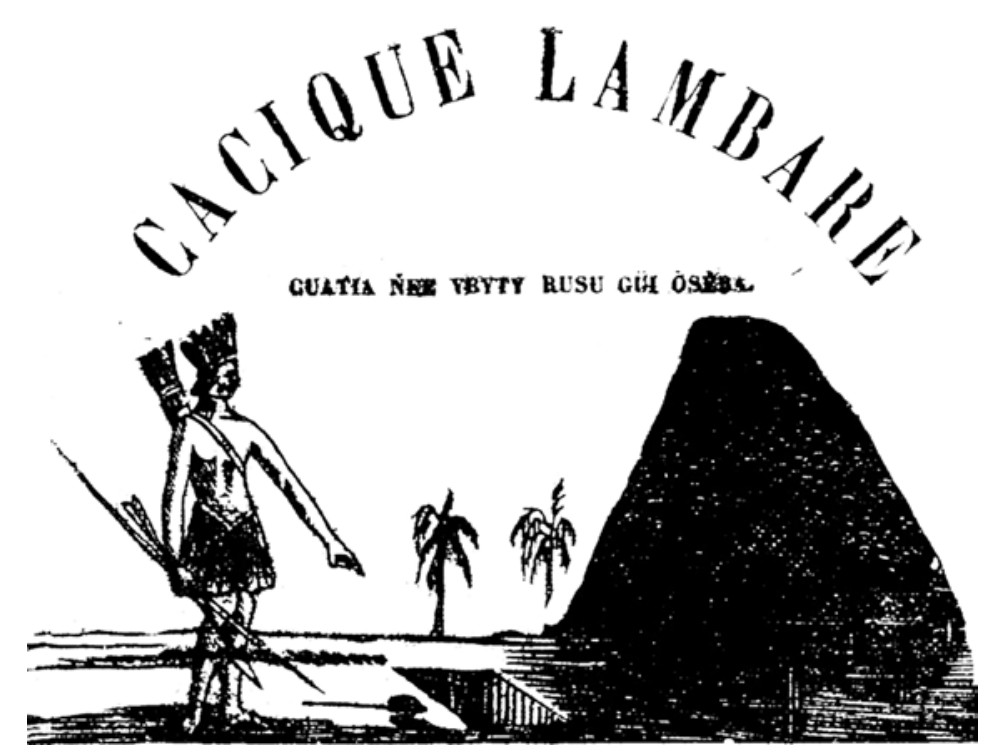

Figura 2. Fuente: Cacique Lambaré, julio - agosto de 1867.

"No cabe pues parangon entre la lucha sostenida por Lambaré contra los españoles, y la guerra que sostiene la República. Aquella traia la luz del cristianismo y la civilizacion y esta el esterminio y la esclavitud. Notable es pues la diferencia. Si no es en este sentido las ideas del cólega, no estaríamos de acuerdo con él”.

Según se expone en Cabichuí, Lambaré fue el "gefe de una tribu belicosa", que sostuvo una fuerte lucha "contra la conquista española que traía ha trescientos años el cristianismo y la civilización":

"Lambaré salvaje convatió la conquista con heroísmo por su amor a su tierra y á la independencia. Pero cedió mas á la voz de la fe, augusta cuna de la civilizacion, que al poder de los elementos del español.

Asi pues donde existía una tribu belicosa se levantó un pueblo civilizado y heróico. Y este pueblo es el que hoy lucha brazo á brazo contra las cadenas y la barbarie con que le amenaza con la feroz guerra q' le hace el Brasil y sus secuaces"48.

Cacique Lambaré respondió a esta crítica de Cabichuí afirmando la dificultad que existe en comparar la conquista española con la guerra "actual", ya que reconocía que los españoles habían traído: “(...) como su bandera la Santa Cruz, por eso ahora todos los nativos están bautizados y tienen cultura, y los que ahora traen la guerra

${ }^{48}$ Cabichuí. Año 1, n²7, 08/08/1867. 
al país tienen las cadenas y la muerte como su bandera". De la herencia indígena el periódico rescató el idioma y el valor de algunos antiguos guerreros; de la herencia española rescató la religión cristina. Así, afirmó que: “(...) desde que Lambaré se hizo cristiano llegó a ser un sincero amigo de los españoles y los ama a pesar de que son de otra nación". Por último, en el mismo artículo afirmó que "a pesar de ser cacique no es abogado del cacicazgo, solo tiene en su propósito progreso, civilización y libertad"49. Estas críticas podrían explicar la razón del cambió de nombre del periódico, el que comenzó a llamarse a partir de entonces solamente Lambaré. El cambio de nombre, asimismo, fue acompañado por un nuevo dibujo en su portada (Figura 3).

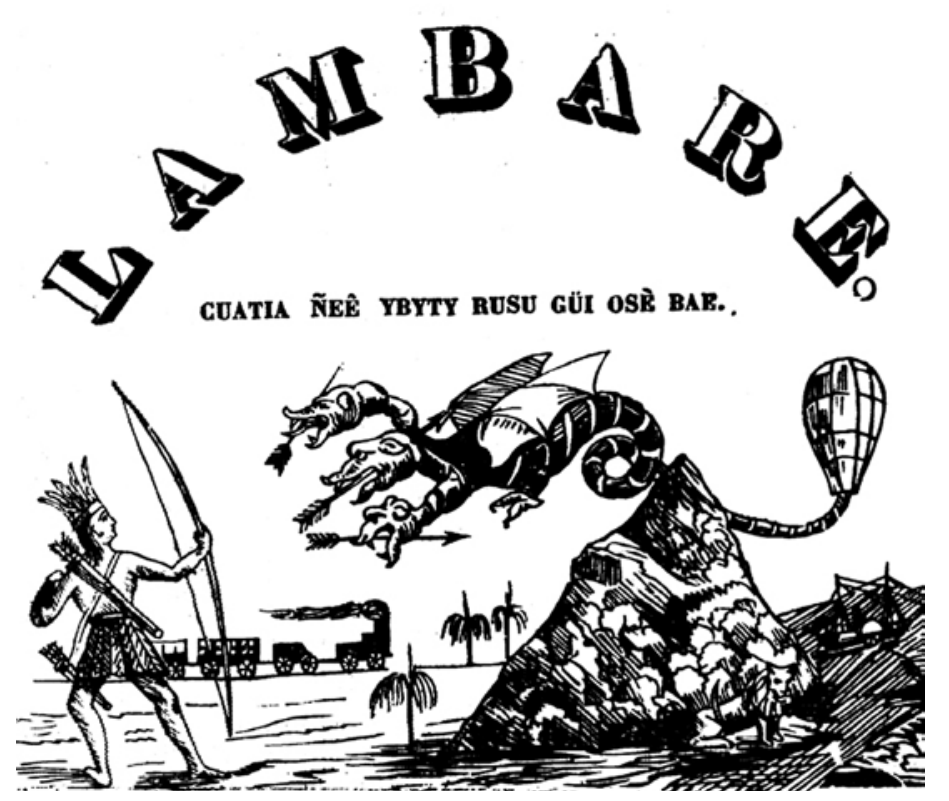

Figura 3. Fuente: Lambaré, septiembre 1867-febrero 1868.

En este nuevo grabado, Lambaré tiene una actitud más combativa, más heroica; lo vemos que ha clavado sus flechas en cada una de las cabezas de ese monstruo que simboliza a la Triple Alianza. A su vez, en esta nueva imagen, lo vemos que no encara en soledad el enfrentamiento, sino que tiene el apoyo del ferrocarril, del arsenal y el barco a vapor, que simbolizan el alto grado de civilización del pueblo paraguayo. A su derecha, la imagen de bravura del león fue usada para representar al Paraguay. En la prensa paraguaya fue ampliamente repetido el león como símbolo de la majestuosidad y poder de la nación paraguaya. Los artículos hacen referencias al "ejército de leones" y al "soldado león", para aludir a la valentía y bravura con la que los paraguayos enfrentaban al "ejército de macacos". El león ${ }^{50}$, "el rey del valor y de la fuerza", simboliza en los

\footnotetext{
${ }^{49}$ Cacique Lambaré, Año 1, n³, 22/08/1867.

50 "El león paraguayo está en pié, sereno, magestuoso y gallardo contemplando los movimientos tortuosos y estratéjicos del cobarde agresor. Nada se escapa á su mirada penetrante, por que ha medido sus atléticas
} 
grabados la valentía del paraguayo que provoca pánico a sus enemigos.

Este cambio pone en evidencia que si bien, como dijimos más arriba, la reivindicación de la lengua guaraní acarreaba la revalorización de la etnia indígena, este proceso no implicaba un rechazo a la conquista española sino, por el contrario, hubo una exaltación de los elementos civilizadores aportados por los españoles. De este modo se pretendía mostrar que los paraguayos actuales no eran "salvajes", sino que eran más civilizados que sus enemigos.

La pérdida del título de Cacique del periódico Lambaré podría estar relacionada, a su vez, con la exaltación que realizó la prensa paraguaya de la persona de Solano López. La construcción del mito de López como padre, principal protector y guerrero número uno del pueblo paraguayo, excluía la exaltación de cualquier otra figura que pudiera generar identificación entre los paraguayos.

En definitiva, más allá del análisis de los elementos simbólicos que implica la utilización del guaraní, la prensa paraguaya tuvo el objetivo pragmático de buscar una ampliación de su público lector, ya que la mayor parte de los paraguayos hablaban exclusivamente guaraní. Si bien es difícil saber cuáles fueron los alcances y los límites de la recepción de los artículos en guaraní aparecidos en los periódicos, ellos persiguieron el objetivo de incorporar a sectores que con anterioridad habían estado excluidos de la práctica de la lectura de la prensa. Es por ello que cuando El centinela saludó la aparición del periódico Cacique Lambaré, afirmó sobre el uso del guaraní:

"El Casique Lambaré. Es el padre del pueblo, cuya ternura y consejos no escacea á la clase proletaria -Habla en guaraní el idioma del corazon, y sabe inflamar el patriotismo, evocando las glorias de nuestros abuelos y haciendo alarde del valor y firmeza de su indómita rasa" ${ }^{51}$.

Hundido en una guerra total el gobierno paraguayo sintió la necesidad de comunicarse con esa "clase proletaria", para que lucharan hasta "vencer o morir" en la guerra que la Triple Alianza traía a su país.

El intento de modificación de las relaciones de dominación lingüística, atestiguada por la expansión del guaraní más allá del ámbito doméstico, no fue un logro permanente. Incluso Estrella, último periódico publicado durante la guerra, no presentó ningún texto escrito en guaraní. Es curioso destacar que así como Cacique Lambaré escribía en guaraní con "la punta de sus flechas", lo que implicaba una asociación simbólica del idioma guaraní con las armas de etnia guaraní, Estrella en cambio, afirmó: "escribimos, por decirlo así con la punta de nuestra espada las impresiones sentidas en

fuerzas, y conoce a palmos sus posiciones. Si deja acercarse al enemigo, es para asegurar el certero golpe, que acabará para siempre con los malditos y ruines sicarios. De hito en hito los mira, los saborea y los fascina sin alterarse, por que conoce la cobardía de sus adversarios, que no resistirá al empuje de su esforzado valor". El Centinela. Año 1, nº16, 08/08/1867, p. 1.

${ }^{51}$ El Centinela. Año 1, nº18, 22/08/1867. 
los combates"52, lo que implicaba una asociación del español con las armas traídas por los conquistadores al suelo americano.

Con la derrota del Paraguay en los campos de batalla la situación cambiaría completamente para el guaraní. En 1870 se reinició la política de exclusión de la lengua guaraní, marginándola nuevamente de las instituciones educativas y también de la prensa (Meliá, 1992). La justificación de estas acciones yacía en la consideración de la lengua guaraní como un signo del atraso paraguayo, como uno de los principales problemas para el desarrollo moderno del Paraguay ${ }^{53}$.

Fue en otro contexto de guerra cuando nuevamente se volvió a conceder prestigio al guaraní. Durante la Guerra del Chaco (1932-1935) se prohibió el uso del español en los campos de batalla y las claves secretas militares fueron cifradas exclusivamente en guaraní. Bartomeu Meliá sostiene que la historia lingüística del Paraguay se ha movido pendularmente entre la guerra y la paz, por lo que se ha vuelto un tópico de los historiadores y sociolingüistas repetir que los conflictos bélicos internacionales paraguayos fueron la causa de la revitalización y supervivencia del guaranís ${ }^{4}$.

\section{Conclusiones}

Durante la guerra las autoridades otorgaron una particular importancia a los periódicos porque entendieron que a través de ellos podrían regular las conductas y modelar las representaciones, en un contexto en el que eran impostergables las necesidades de movilizar moralmente a la población y de garantizar la defensa de la identidad en peligro. Los periódicos de trinchera presentan en sus páginas nuevos tipos de textos, en guaraní y en español, escritos con estilos diferentes y en tono satírico, ubicados en un formato también novedoso, acompañados por xilografías. Todas esas innovaciones partieron de la atribución de ciertas expectativas y competencias al público al que estaban dirigidos. Los directores, los redactores de los textos y los grabadores apostaron al saber previo de sus lectores con el propósito de lograr una mayor comprensión de lo que se transmitía. Al mismo tiempo que trabajaban en los periódicos estos individuos servían en el ejército. De esta manera, tanto los productores

\footnotetext{
${ }^{52}$ Estrella, Año 1, nº ${ }^{\circ}, 24 / 02 / 1869$.

${ }^{53}$ El diario El País publicó el 3 de marzo de 1939: "el Paraguay tiene un gran enemigo de su progreso en el idioma guaraní (...) Como idioma de la barbarie, entorpece la lengua”.

${ }^{54}$ En la Constitución paraguaya de 1967 se estableció en el art. 5: "Los idiomas nacionales de la República son el guaraní y el español. Será de uso oficial el español”. En el art. 92 se dictaminó que: “El Estado fomentará la cultura en todas sus manifestaciones. Protegerá la lengua guaraní, y promoverá su enseñanza, evolución y perfeccionamiento". El Ministerio de Educación y Culto introdujo la enseñanza sistemática del guaraní en diversos niveles y grados. Las principales disposiciones se orientaron a la formación de profesores de guaraní y a la enseñanza de esta lengua como asignatura especial en algunas escuelas. Recién en 1990 se declaró obligatoria la inclusión de los dos idiomas nacionales en el curriculum educativo. En la Constitución de 1992, en el art. 140, se estableció que: "El Paraguay es un país pluricultural y bilingüe. Son idiomas oficiales el castellano y el guaraní. La Ley establecerá las modalidades de utilización de uno y de otro. Las lenguas indígenas, así como las de otras minorías, forman parte del patrimonio cultural de la Nación".
} 
como los consumidores de esos periódicos de trinchera estaban comprometidos activamente con la guerra.

El uso simultáneo de diferentes estilos en los artículos del periódico, demuestra que los redactores fueron conscientes de su deber de crear un nuevo tipo de órgano periodístico en Paraguay pensado para un público lector específico: los soldados paraguayos. El uso de expresiones coloquiales o vulgares perseguía el fin de exponer a sus lectores lo más claramente posible las opiniones y reflexiones de los periódicos. Para la elaboración de los textos satíricos los redactores aprovecharon los discursos en circulación entre la tropa. De esta manera, su inclusión constituye una de las estrategias dirigidas a que los soldados generasen una identificación con estos periódicos que imitaban sus expresiones y su habla cotidiana.

Ya sea que los artículos estuviesen escritos en un estilo elevado, medio o simple, todos ellos fueron atribuidos a redactores ficticios o personajes-símbolo. Cada periódico de trinchera creó sus propios personajes-símbolo que con nombres homónimos a cada periódico actuaban como sus redactores. La creación de estos personajes-símbolo fue otra de las estrategias de la propaganda, ya que a través de ellos se intentaba convencer de la validez de las opiniones expresadas porque provenían de "gente común" que había permanecido ajena a la práctica de escritura periodística pero que, dadas las circunstancias de la invasión aliada, habían tomado la pluma para combatir a los enemigos. Estos personajes-símbolo usaban un lenguaje coloquial para lograr una mayor difusión entre un público que anteriormente no había tenido acceso a los periódicos.

Otra de las innovaciones producidas en la prensa fue la aparición de periódicos escritos en guaraní. En Paraguay el idioma español había sido relacionado con la civilización y el progreso, motivo por el cual se había impuesto como la lengua legítima de la burocracia y de las prácticas sociales letradas. El guaraní, en cambio, era sinónimo de atraso y por lo tanto había sido relegado al ámbito privado. Sin embargo, durante la guerra hubo un intento de transformación de las relaciones de dominación lingüística, establecidas en la sociedad paraguaya antes del conflicto, a partir de la difusión del guaraní por los periódicos de trinchera. Esto significó una reivindicación del idioma guaraní, que no solo abandonaba el ámbito en el cual había sido relegado sino que además comenzaba a ser considerado como lengua nacional del Paraguay.

La utilización del guaraní por la prensa paraguaya tuvo un objetivo pragmático: buscar una ampliación del público lector, ya que la mayor parte de los paraguayos eran monolingües. Esa reivindicación del guaraní acarreaba la revalorización del pasado indígena. A través de la lengua se estableció una conexión entre las hazañas guerreras de los guaraníes y la guerra contra la Triple Alianza, de esta manera se entroncaba la identidad nacional paraguaya con sus raíces indígenas. Sin embargo, esta reivindicación no llegó a plantear críticas a la conquista española, sino que por el contrario, el cristianismo y la civilización heredados de los conquistadores eran considerados como el origen del progreso del país. 


\section{Periódicos}

Cacique Lambaré. Edición facsimilar. 1995. Asunción, Imprenta Nacional.

Cabichuí. Periódico de la guerra de la Triple Alianza. Edición facsimilar compilada por Escobar, Ticio y Salerno, Osvaldo. 1984. Asunción, Museo del Barro.

El Centinela. Colección del semanario de los paraguayos en la guerra de la Triple Alianza. 1867. Edición facsimilar de Vázquez, José Antonio. 1964. Buenos Aires, Paraquariae.

Estrella. 1869. Colección de la Biblioteca Nacional del Paraguay.

\section{Referencias Bibliograficas}

Altamirano, Carlos (dir.) 2002. Términos críticos de la sociología de la cultura. Buenos Aires, Paidós.

Beattie, Peter. 2001. The tribute of blood: army, honor, race, and nation in Brazil, 1864-1945. Duke University Press, Durham.

Bourdieu, Pierre. 1990. Sociología y cultura. México, Grijalbo.

Caballero Campos, Hérib y Ferreira Segovia, Cayetano. 2007. "El Periodismo de Guerra en el Paraguay (1864-1870)". En: Richard, Nicolas, Capdevila, Luc y Boidin, Capucine (dir.). Les guerres du Paraguay aux XIXe et XXe siècles. París, CoLibris.

Capdevila, Luc. 2010. Una guerra total: Paraguay, 1864-1870. Ensayo de historia del tiempo presente. Buenos Aires, CEADUC/Editorial SB.

Centurión, Juan Crisóstomo (sin fecha de ed.) Memorias o reminiscencias históricas sobre la Guerra del Paraguay. Tomo I - IV. Asunción, Ed. Guarania.

Cuarterolo, Miguel Ángel. 2000. Soldados de la memoria. Imágenes y hombres de la Guerra del Paraguay. Buenos Aires, Planeta.

Doratioto, Francisco. 2008. Maldita guerra. Nueva historia de la guerra del Paraguay. Buenos Aires, Emecé.

González Torres, Dionisio. 1989. Sobre la grafía del Guarani-Revisión bibliográfica desde el siglo XVI. Asunción, S.P.I.

Johansson, María Lucrecia. 2010. "Estado, guerra y actividad periodística durante la guerra del Paraguay (1864-1870)”. En: Anuario del Centro de Estudios Históricos “Prof. Carlos S. A. Segreti”, año 10, N¹0, Córdoba (Argentina), pp. 189-210.

periodístico paraguayo durante la Guerra de la Triple Alianza(186 Crítica, Revista del Departamento de Historia de la Facultad de Ciencias Sociales de la Universidad de San Andrés, Nº47, Bogotá (Colombia), Mayo-Agosto de 2012, pp. 71-92.

Lustig, Wolf. 2007. “¿El guaraní lengua de guerreros? La raza guaraní y el avañe’e en el discurso bélico-nacionalista del Paraguay“. En: Richard, Nicolas, Capdevila, Luc y Boidin, Capucine (dir.). Les guerres du Paraguay aux XIXe et XXe siècles. París, CoLibris.

Meliá, Bartomeu. 1992. La lengua guaraní del Paraguay. Historia, sociedad y literatura. Madrid, Mapfre.

Plá, Josefina. 1984. El grabado: instrumento de la defensa. Museo del Barro, Asunción.

Thompson, George. 1910. La guerra del Paraguay. Buenos Aires, Ed. Juan Palumbo.

Toral, André. 2001. Imagens em Desordem. A iconografia da Guerra do Paraguai (1864-1870). São Paulo, Humanitas FFLCH/USP.

Villagra-Batoux, Delicia. 2002. El guaraní paraguayo: de la oralidad a la lengua literaria. Asunción, Ambassade de France au Paraguay \& Expolibro. 
Whigham, Thomas. 2010. La guerra de la Triple Alianza. Vol. I. Causas e inicios del mayor bélico de América del Sur. Asunción, Taurus.

2011. La guerra de la Triple Alianza. Vol. II. El triunfo de la violencia, el fracaso de la paz. Asunción, Taurus.

2012. "Building the Nation While Destroying the Land: Paraguayan Journalism during the Triple Alliance War, 1864-1870". En: Jahrbuch für Geschichte Lateinamerikas, vol. 49, (en prensa).

Zarratea, Tadeo. 2002. Gramática elemental de la Lengua Guaraní. Asunción, ed. Marben. 